\title{
Examination of pelvic anatomy by section plastination technique
}

\author{
Erengül Boduç ${ }^{1}$ (D), Okan Bilge ${ }^{2}$ (D), Servet Çelik ${ }^{2}$ \\ ${ }^{1}$ Department of Anatomy, Faculty of Medicine, Kafkas University, Kars, Turkey \\ ${ }^{2}$ Department of Anatomy, Faculty of Medicine, Ege University, Izmir, Turkey
}

\begin{abstract}
Objectives: The aim of this study was to provide long-term preservation of the pelvic coronal cross-sections using plastination technique. Thus, we intended to provide a better understanding of the three-dimensional anatomy of the pelvis for education and research purposes.

Methods: The standard plastination method was combined with the section plastination technique. The coronal pelvis sections of $8 \mathrm{~mm}$ thickness were passed through the plastination stages. At these stages, unlike the techniques in the literature, surgical aspirator was used for cleaning the surfaces of the sections and xylene was used for lightening the plastinates.

Results: At the end of the plastination stages, the sections preserved the real color and texture extremely well. Sections were dry, odorless, hygienic and could be handled without special precaution. Moreover, anatomical details were very clear and understandable, so that any structure could be measured photogrammetrically.

Conclusion: Examination of the pelvic anatomy with coronal sections via plastination method could be very effectively used in education and research. In this way, a technological and up-to-date innovation can be provided for the development and understanding of three-dimensional anatomy. Real examination of cross-sectional anatomy instead of virtual radiological images can provide a useful and effective tool for both students and researchers.
\end{abstract}

Keywords: 3D anatomy; plastination; pelvis; sectional anatomy

Anatomy 2020;14(3):227-230 @2020 Turkish Society of Anatomy and Clinical Anatomy (TSACA)

\section{Introduction}

Plastination is a preservation technique which was developed by Gunther Von Hagens in Heidelberg, Germany in $1978 .^{[1,2]}$ The importance of dissection in anatomy education is well known for long years. ${ }^{[3]}$ Combining traditional cadaver dissection with plastination technique provides a more effective education and research. ${ }^{[2]}$

The plastination technique relies on replacement of tissue water and lipids by cured polymers in four steps: dehydration, degreasing, forced impregnation and curing. ${ }^{[4,5]}$ Plastinated specimens are easy to handle, durable, hygienic and convenient to use in the laboratory practice, combining reality with modernity. ${ }^{[3]}$ Since it is an educational tool that can keep up with developing technology, it has succeeded to be an interesting educational tool preferred by students. ${ }^{[2,6]}$ Recent studies showed that plastinated specimens are useful materials not only for the anatomy but also in other fields such as histology, pathology, radiology and microsurgery. ${ }^{[7-11]}$
The anatomy of the pelvis is very important for surgical interventions in both men and women. ${ }^{[12]}$ Operations such as tumor surgeries made within the pelvic fasciae requires a detailed pelvic anatomy knowledge. ${ }^{[13,14]}$ Orientation to three-dimensional and cross-sectional anatomy of the pelvis is crucial to provide a comprehensive adaptation to the pelvic region. ${ }^{[13,15]}$ Examination of the cross-sectional anatomy of the pelvis with the plastination technique can be beneficial for both education and research purposes. ${ }^{[12,13,15]}$

In this study, the pelvis of a male cadaver was sectioned into $8 \mathrm{~mm}$ thick coronal slices and plastinated using silicone plastination technique. The benefits of the cross-sectional plastination technique has been revealed by previous studies in terms of understanding the threedimensional anatomy. ${ }^{[12,15-18]}$ Therefore, the aim of this study was to show the effectiveness of the cross-sectional plastination technique on pelvis for to provide a better 
understanding of the three-dimensional pelvic anatomy for education and research purposes.

\section{Materials and Methods}

The study was conducted on a single pelvis of a male cadaver previously embalmed by $10 \%$ formalin. The specimen was first washed under running tap water for 24 hours. After draining excess water, the sample was kept at $+4^{\circ} \mathrm{C}$ overnight, and freezed for two days at $-20^{\circ} \mathrm{C}$ and 5 days at $80^{\circ} \mathrm{C}$. A band saw was used to get $8 \mathrm{~mm}$ thick coronal slices. Using a surgical aspirator and manual water spray, sawdust adhering to the section surface during cutting was removed.

Before dehydration step, sections were placed in a tight-cap container in the coronal order from front to back, using thin separators between them. Cold acetone is preferred to minimize the shrinkage ${ }^{[13,19]}$ At the end of three months, in a graded series $(95 \%-97 \%-100 \%)$ of cold acetone baths $\left(-20^{\circ} \mathrm{C}\right)$, dehydration was finished. The specimens were kept in its last acetone bath for one week at room temperature for degreasing.

In impregnation step we followed up two different protocols: First, we used xylene added (S/X ratio: 1/0.6) silicone reaction mixture $(\mathrm{S} 10+\mathrm{S} 3$, Biodur Products $\mathrm{GmbH}$, Heidelberg, Germany) as described by Steinke et al. ${ }^{[20]}$ second, the impregnation was performed intermittently at room temperature as described by Tianzhong et al. ${ }^{[21]}$ Curing of impregnated slices carried out in a gas-curing chamber in which the specimens exposed to silicone hardener (S6 Biodur Products GmbH, Heidelberg, Germany) vapor again at room temperature. The added xylene removed out from the slices using vacuum chamber (KenaTek Inc., Izmir, Turkey) after the curing process. ${ }^{[2]}$

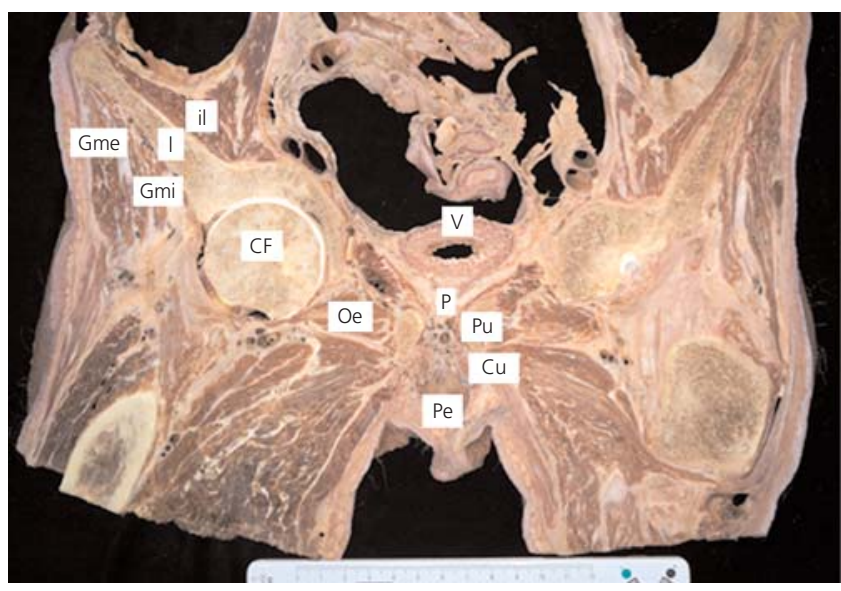

Figure 2. Anatomical details on a coronal section. CF: head of the femur; Cu: crus penis; I: ileum; il: iliacus; Gme: gluteus medius; Gmi: gluteus minimus; Oe: obturatorius externus; P: prostate; Pe: penis; Pu: pubis; V: urinary bladder.

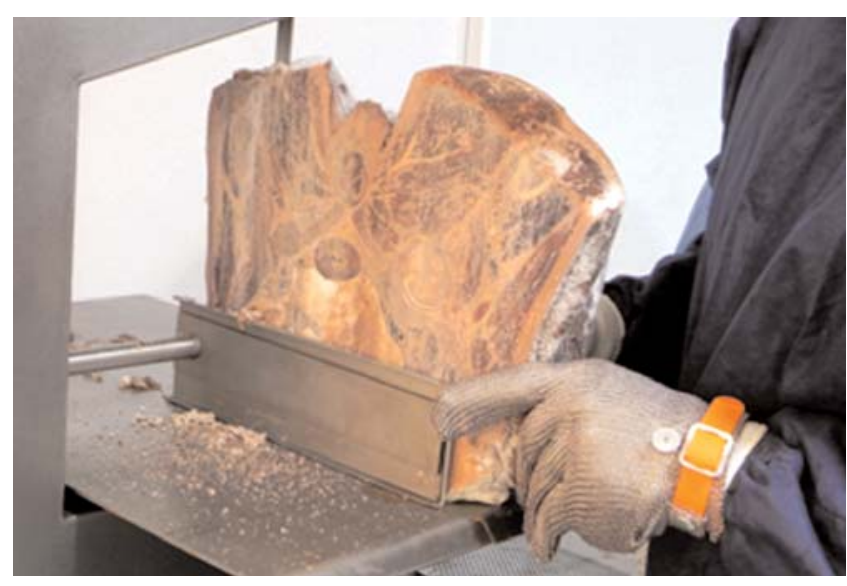

Figure 1. Sectioning stage (coronal).

\section{Results}

After curing and removing out the xylene, a series of coronal sections of pelvis were obtained (Figure 1). The sections had clearly determined details of many anatomical structures comparable with radiological images. The articular relations, cartilaginous surfaces, muscles with their origins and/or insertions and neuro-vascular structures were clearly observed (Figure 2). Sections were dry, odorless, hygienic and can be handled without spoiling. Cleaning surfaces by using surgical aspirator and water spray has enabled anatomical structures and details to be revealed more clearly and uniformly. There were no rough field or artefacts due to residual sawdust on the final products. It was shown that measurements can made directly on samples, as well as more detailed measurements on the computer from the photographs taken (Figure 3).

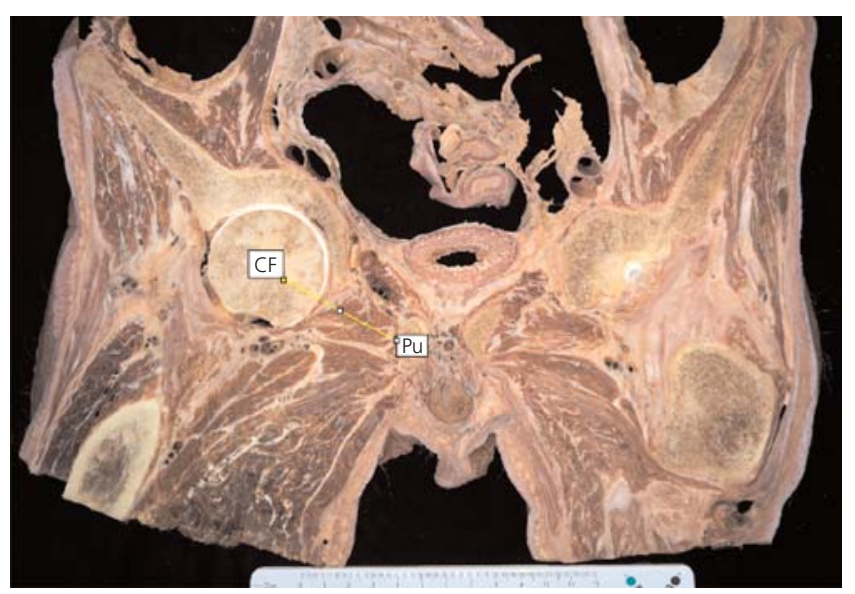

Figure 3. Photogrammetric measurement on a cross section (for example: measuring the distance between femur and pubis). CF: head of the femur; Pu: pubis. 


\section{Discussion}

Anatomy is taught in a traditional systematic way in most of the medical schools or faculties. ${ }^{[23,24]}$ Along with clinic and surgical education in advanced classes, the students are also expected to adapt cross-sectional anatomy particularly when interpreting radiological images. Adaptation to cross sectional anatomy necessitates understanding and comprehending the structures beyond the systematic anatomy thus may cause anxiety to students who learned anatomy with a traditional approach. Therefore, it is suggested to acquire new and diverse tools in accordance with the developing technology. ${ }^{[25,26]}$

One of the most popular methods demonstrating three-dimensional anatomy is the plastination technique. ${ }^{[3]}$ This technique has some advantages and disadvantages. ${ }^{[6]}$ The advantages of plastination are that the whole body, parts or organs can be made palpable, hygienic, odorless and durable, preserving the perception of reality. ${ }^{[6,19]}$ Plastinating especially the parts of the cadavers that have complex anatomy enables the three-dimensional understanding of the anatomy with a more comfortable training tool. $^{[13]}$

Anatomical structures begin to deteriorate after a certain time in cadavers or cadaveric parts preserved in embalming solutions. It is very difficult to preserve the cross-sectioned structures in an embalming solution since their integrity breaks down in a very short time. Particularly, the parts of the thin sections in the solution can easily be separated from each other and it becomes difficult to demonstrate. Plastination is suggested to be one of the best preservation methods for the cross-sectional anatomical structures. ${ }^{[2]}$ When compared to learn the cross-sectional anatomy from atlases and radiological images, plastinated materials provide better orientation to adapt the three dimensional anatomy with the comfort of seeing, holding and examining the real structure. In this way, learning the relationships of the structures within a given section becomes more satisfying. ${ }^{[6,13,15,19]}$ The disadvantages of the plastination method are that the materials and devices used are expensive. ${ }^{[6,19]}$ In addition, the toxic effects of the chemicals used during the procedure should not be ignored. ${ }^{[27]}$

Clinical significance of pelvic region is different in women and men. ${ }^{[12]}$ Knowledge of anatomy of the pelvis is very important especially for the surgeons operating within the pelvis. $\left[{ }^{13]}\right.$ Plastinated specimens are useful tools for comprehension of the detailed anatomy of the body regions. Sheet plastination materials are prepared using epoxy and polyester resins. ${ }^{[11,12,28]}$ In this study, the plastination of $8 \mathrm{~mm}$ coronal sections of a male pelvis, inspired by the sheet plastination technique, was performed by sili- cone plastination of the body parts. Silicone plastination is a convenient option to prepare cross-sectional materials for laboratories that do not have adequate equipment or experience to make epoxy and polyester sheet plastinates. One of the important details of our method is adding xylene to the silicone mixture that provides low cost and low weight. Cleaning slices with a surgical aspirator provided a clean and artifact-free surface much more easily. In addition to this, taking photographs from the samples with a scale may allow to morphometric studies and researches relying on photogrammetric measurements through appropriate software on the computer.

\section{Conclusion}

The use of plastinated products have significant contributions to both education and research. In this way, the cross-sectional anatomy displayed in the virtual area can be perceived with a real material. We suggest that the examination of the pelvis sections in the coronal plane with the silicone plastination technique will provide a useful tool for adaptation to three dimensional anatomy of the pelvic region.

\section{Conflict of Interest}

No conflict declared by the authors.

\section{Author Contributions}

All authors equally contributed to concept, design and writing manuscript.

\section{Ethics Approval}

The study was approved by the ethics committee of Ege University Faculty of Medicine (Approval number: 201812.1/38). The study was performed following the aid of the ethical standards down in the 1964 Declaration of Helsinki and its later amendments.

\section{Funding}

The authors declared no financial support for this study.

\section{References}

1. Ottone NE, Cirigliano V, Lewicki M, Bianchi HF, Aja-Guardiola S, Algieri RD, Fuentes R. Plastination technique in laboratory rats: an alternative resource for teaching, surgical training and research development. International Journal of Morphology 2014;32:1430-5.

2. Latorre R, Bainbridge D, Tavernor A, López Albors O. Plastination in anatomy learning: an experience at Cambridge University. J Vet Med Educ 2016;43:226-34.

3. Latorre RM, García-Sanz MP, Moreno M, Hernández F, Gil F, López O, Henry RW. How useful is plastination in learning anatomy? J Vet Med Educ 2007;34:172-6. 
4. Sora MC, Jilavu R, Matusz P. Computer aided three-dimensional reconstruction and modeling of the pelvis, by using plastinated cross sections, as a powerful tool for morphological investigations. Surg Radiol Anat 2012;34:731-6.

5. Ottone NE, Baptista CA, Latorre R, Bianchi HF, Del Sol M, Fuentes R. E12 sheet plastination: techniques and applications. Clin Anat 2018;31:742-56.

6. Riederer BM. Plastination and its importance in teaching anatomy. Critical points for long-term preservation of human tissue. J Anat 2014:224:309-15.

7. Dawson TP, James RS, Williams GT. Silicone plastinated pathology specimens and their teaching potential. J Pathol 1990;162:265-72.

8. Bickley HC, Walker AN, Jackson RL, Donner RS. Preservation of pathology specimens by silicone plastination: an innovative adjunct to pathology education. Am J Clin Pathol 1987;88:220-3.

9. Diao Y, Liang L, Yu C, Zhang M. Is there an identifiable intact medial wall of the cavernous sinus? Macro-and microscopic anatomical study using sheet plastination. Neurosurgery 2013;73:106-10.

10. Sora MC, Strobl B, Staykov D, Traxler H. Optic nerve compression analyzed by using plastination. Surg Radiol Anat 2002;24:205-8.

11. Ottone NE, del Sol M, Fuentes R. Report on a sheet plastination technique using commercial epoxy resin. International Journal of Morphology 2016;34:1039-43.

12. Beyersdorff D, Schiemann T, Taupitz M, Kooijman H, Hamm B, Nicolas V. Sectional depiction of the pelvic floor by CT, MR imaging and sheet plastination: computer-aided correlation and 3D model. Eur Radiol 2001;11:659-64.

13. Sora MC, Erman G, Pirtea L, Boia M, Matusz P, Sas I. Three dimensional reconstruction and modeling of complex pelvic anatomical structures by using plastinated cross sections. Materiale Plastice 2015;52:381-4.

14. Al-Ali S, Blyth P, Beatty S, Duang A, Parry B, Bissett IP. Correlation between gross anatomical topography, sectional sheet plastination, microscopic anatomy and endoanal sonography of the anal sphincter complex in human males. J Anat 2009;215:212-20.

15. Sora MC, Jilavu R, Matusz P. Computer aided three-dimensional reconstruction and modeling of the pelvis, by using plastinated cross sections, as a powerful tool for morphological investigations. Surg Radiol Anat 2012;34:731-6.

16. Sora MC, Jilavu R, Grübl A, Genser-Strobl B, Staykov D, Seicean A. The posteromedial neurovascular bundle of the ankle: an anatomic study using plastinated cross sections. Arthroscopy 2008;24:258-63.

17. Qiu MG, Zhang SX, Liu ZJ, Tan LW, Wang YS, Deng JH, Tang ZS. Plastination and computerized $3 \mathrm{D}$ reconstruction of the temporal bone. Clin Anat 2003;16:300-3.

18. Sora MC, Genser-Strobl B. The sectional anatomy of the carpal tunnel and its related neurovascular structures studied by using plastination. Eur J Neurol 2005;12:380-4.

19. Suganthy J, Francis DV. Plastination using standard S10 techniqueour experience in Christian medical college, Vellore. Journal of Anatomical Society of India 2012;61:44-7.

20. Steinke H, Rabib S, Saitoc T, Sawuttic A, Miyakic T, Itohe M, Spanel-Borowskia K. Light-weight plastination. Ann Anat 2008;190: 428-31.

21. Tianzhong $Z$, Jingren L, Kerming Z. Plastination at room temperature. Journal of the International Society of Plastination 1998;13:215.

22. Bilge O, Çelik S, Yörük MD, Koçer IB. Useful materials for crosssectional anatomy education: silicone plastinated examples of foot and hand. Austin Journal of Anatomy 2018;5:1080-4.

23. Murgitroyd E, Madurska M, Gonzalez J, Watson A. 3D digital anatomy modelling-practical or pretty? Surgeon 2015;13:177-80.

24. Hoyek N, Collet C, Di Rienzo F, De Almeida M, Guillot A. Effectiveness of three-dimensional digital animation in teaching human anatomy in an authentic classroom context. Anat Sci Educ 2014;7:430-7.

25. Estai M, Bunt $\mathrm{S}$. Best teaching practices in anatomy education: a critical review. Ann Anat 2016;208:151-7.

26. Sugand K, Abrahams P, Khurana A. The anatomy of anatomy: a review for its modernization. Anat Sci Educ 2010;3:83-93.

27. Holladay SD, Blaylock BL, Smith BJ. Risk factors associated with plastination: I. Chemical toxicity considerations. Journal of the International Society of Plastination 2001;16:9-13.

28. Sargon MF, Tatar I. Plastination: basic principles and methodology. Anatomy 2014;8:13-18.
ORCID ID:

E. Boduç 0000-0001-8872-1993; O. Bilge 0000-0002-8993-2271;

S. Çelik 0000-0002-1102-4417
Correspondence to: Erengül Boduç, PhD

Department of Anatomy, Faculty of Medicine, Kafkas University,

Merkez Mahallesi, Kampus, 36100, Kars, Turkey

Phone: +90 5307849586

e-mail: erenboduc@gmail.com

Conflict of interest statement: No conflicts declared.

This is an open access article distributed under the terms of the Creative Commons Attribution-NonCommercial-NoDerivs 4.0 Unported (CC BY-NCND4.0) Licence (http://creativecommons.org/licenses/by-nc-nd/4.0/) which permits unrestricted noncommercial use, distribution, and reproduction in any medium, provided the original work is properly cited. How to cite this article: Boduç E, Bilge O, Çelik S. Examination of pelvic anatomy by section plastination technique. Anatomy 2020;14(3):227-230. 